\title{
Effects of fusion and conservative treatment on disc degeneration and rates of subsequent surgery after thoracolumbar fracture
}

\author{
Anthony D'Oro, BA, ${ }^{1}$ Mark J. Spoonamore, MD, ${ }^{2}$ Jeremiah R. Cohen, BS, ${ }^{3}$ Frank L. Acosta, MD, ${ }^{4}$ \\ Patrick C. Hsieh, MD, ${ }^{4}$ John C. Liu, MD, ${ }^{4}$ Thomas C. Chen, MD, PhD, ${ }^{4}$ Zorica Buser, PhD, ${ }^{2}$ and \\ Jeffrey C. Wang, MD²
}

\begin{abstract}
${ }^{1}$ Program in Biological Sciences, Weinberg College of Arts and Sciences, Northwestern University, Evanston, Illinois; Departments of ${ }^{2}$ Orthopaedic Surgery and ${ }^{4}$ Neurological Surgery, Keck School of Medicine, University of Southern California, Los Angeles; and 'Department of Orthopaedic Surgery, David Geffen School of Medicine, University of California, Los Angeles, California
\end{abstract}

OBJECT The objective of this study was to compare the incidence of degeneration and need for subsequent fusion surgery between patients who were treated nonsurgically and patients treated with fusion after a diagnosis of thoracicor lumbar-level fracture without degenerative disease.

METHODS The authors performed a retrospective study of Orthopedic United Healthcare patients diagnosed with thoracic or lumbar fracture. Patients were filtered into thoracic and lumbar fracture groups using diagnostic codes and then assigned to one of 2 treatment subgroups (fusion surgery or no surgery) on the basis of procedural codes. Disc degeneration and follow-up surgery were recorded. Chi-square statistical analysis was used.

RESULTS Of 3699 patients diagnosed with a thoracic fracture, 117 (3.2\%) underwent thoracic fusion and 3215 (86.9\%) were treated nonsurgically. Within 3 years, 147 (4.6\%) patients from the nonsurgical subgroup and fewer than 11 $(0.9 \%-8.5 \%)$ from the fusion subgroup were diagnosed with thoracic disc degeneration. From the nonsurgical subgroup, $11(0.3 \%)$ patients underwent a thoracic surgery related to disc degeneration compared with zero from the fusion group $(p>0.05)$. Of 5016 patients diagnosed with lumbar fracture, $150(3.0 \%)$ underwent fusion and $4371(87.1 \%)$ had no surgery. Within 3 years, 503 patients (11.5\%) from the nonsurgical subgroup and $35(23.3 \%)$ from the fusion subgroup were diagnosed with lumbar disc degeneration $(p<0.05)$. From the nonsurgical subgroup, $42(1.0 \%)$ went on to have surgery related to disc degeneration, compared with fewer than $11(0.7 \%-6.7 \%)$ from the fusion subgroup (values not precise due to privacy limitations).

CONCLUSIONS Fusion surgery for thoracic fracture does not appear to increase the likelihood of undergoing future surgery. In the lumbar region, initial fusion surgery appears to increase the incidence of disc degeneration and could potentially necessitate future surgeries.

http://thejns.org/doi/abs/10.3171/2015.7.SPINE15442

KEY WORDS fusion; disc degeneration; follow-up surgery; trauma

$\mathrm{T}$ HERE is significant controversy regarding the role of fusion on the progressive degeneration of the spine. Varying but high incidences of adjacent-segment degeneration following fusion have been reported. .,10,16 $^{2}$ Following anterior lumbar interbody fusion, one prospective study reported an adjacent-level disc degeneration incidence of $32 \%,{ }^{16}$ while another reported $45 \% .{ }^{11}$ Other studies have also discussed the role of fusion in degeneration through the same general region of the spine. ${ }^{6,17}$
Lehmann et al. reported an equal incidence of $58 \%$ at both the adjacent level and the level adjacent to the adjacent level to the lumbar fusion. ${ }^{17}$

Other studies have compared disc degeneration between patients who did and did not undergo a fusion procedure. In a prospective study analyzing posterolateral fusion, a disc degeneration incidence of $38 \%$ was reported for fusion patients as compared with zero for patients who never underwent surgery and were advised to exercise. ${ }^{5}$ 
Moreover, there is disagreement with respect to comparison of clinical outcomes between patients treated with fusion and those treated nonsurgically. In a study published in 2014, Mannion et al. reported that while fusion surgery led to increased disc degeneration, such degeneration had no statistically reliable influence on pain or disability. ${ }^{12}$ This was less conclusive than a previous study, which reported that fusion surgery did indeed reduce pain and improve functionality. ${ }^{15}$ The results of a more recent study from Wood et al. (published in 2015) suggested that after a stable burst fracture, while clinical differences are minimal at short-term follow-up between operative and nonoperative treatment groups, patients from the nonoperative group report less pain and better function at longterm follow-up. ${ }^{21}$ The debate as to whether fusion plays a role in the development of symptomatic degeneration in areas near the fusion or whether the degeneration is a result of a natural progression of arthritic changes continues to be a huge controversy.

Fusion treatment typically includes open reduction and internal fixation with instrumentation while nonoperative treatment consists of external bracing and a period of bed rest. $^{1-3,20}$ Surgical intervention offers immediate stability, correction of spinal misalignment, protection against future neurological impairment, and shorter lengths of stay at treatment facilities. ${ }^{8,14,15,19,20}$ Nonsurgical treatment, however, avoids the risks associated with surgery, which include infection, instrumentation failure, and iatrogenic injury. ${ }^{13,20}$ Previous studies have reported positive outcomes for nonsurgical patients who present with no neurological impairment, supporting the legitimacy of nonsurgical treatment as an alternative to surgery in such circumstances, although with slower recovery times. ${ }^{2-4,7,9}$

Sears et al. reported in 2011 that patients who underwent posterior lumbar arthrodesis had a $2.5 \%$ annual incidence of surgery for adjacent-segment disease following their initial surgery. ${ }^{18}$ However, the patients included in that study were not initially treated for fracture, and the incidence of follow-up surgery was not compared with initial nonoperative treatment. To our knowledge, no study published to date has analyzed the likelihood of developing degeneration and requiring a surgery after conservative management of thoracolumbar fractures. Additionally, we have found no studies that report these rates in the thoracic region.

In the present study, we sought to establish a more conclusive comparison between initial fusion surgery and nonsurgical treatment regarding the risk of developing disc degeneration and the subsequent requirement of surgery in both the thoracic and lumbar regions. We used a population of patients treated for nondegenerative conditions to better elucidate the development of degeneration and the need for further surgery.

\section{Methods}

Using the PearlDiver Patient Record Database (PearlDiver Technologies, Inc. http://www.pearldiverinc.com/), we divided patients into groups based on Current Procedural Terminology (CPT) and the International Classification of Diseases, Ninth Edition (ICD-9) insurance billing codes. The database consists of patient records from Medicare and a collection of private-payer insurance companies, the largest of which is UnitedHealth Group. The patient population spans all age groups and represents geographic areas throughout the entire United States, although the South has the most patients due to the predominance of UnitedHealth insurance.

We used ICD-9 diagnostic codes to identify all patients who presented with either thoracic- or lumbar-level fracture in the year 2007 (Table 1). Patients who were diagnosed with disc degeneration (as demonstrated by a billing code) at the time of the fracture diagnosis were excluded from the study. There are no codes that define the severity of fracture or trauma, so all thoracic and lumbar fractures were included in each respective group. For both the thoracic- and lumbar-level groups, we divided patients into 2 subgroups: those who underwent a fusion procedure within 90 days of fracture and those who underwent conservative treatment within 90 days. For both the surgical and nonsurgical subgroups, we then used ICD-9 diagnostic codes to determine how many patients went on to be diagnosed with disc degeneration in their respective regions (thoracic or lumbar) within 1,2 , or 3 years of their initial treatment. The number of patients with disc degeneration after 3 years includes all patients who were diagnosed with disc degeneration from the time of the initial treatment through 3 years thereafter. For those patients, we used CPT and ICD-9 procedural codes to identify how many patients underwent an operation related to disc degeneration within 1 year after the disc degeneration diagnosis. We used chi-square analysis to determine whether there was a statistically significant difference in the likelihood of undergoing a future surgical procedure between the initial fusion and nonsurgical subgroups in both the thoracic and lumbar fracture groups. We also used chi-square to compare the yearly incidences of same-region disc degeneration between the fusion and nonsurgical subgroups.

\section{Results}

\section{Thoracic Region}

The thoracic fracture cohort included 3699 patients who were diagnosed with a thoracic-level fracture in 2007. No statistical significance was found for age, sex, or region in determining which patients were treated with fusion rather than nonsurgically ( $p>0.05$, Fig. 1). Thoracic fractures were more common in male patients (Fig. 2), and the prevalence was highest in the 50- to 54-year age group (n $=421,11.4 \%$ ), followed closely by the 60 - to 64 -year, 55 to 59-year, and 45- to 49-year age groups $(11.0 \%, 10.2 \%$, and $9.0 \%$, respectively, Fig. 3).

Of the 3699 patients diagnosed with thoracic fracture, 117 patients $(3.2 \%)$ were treated with fusion surgery and 3215 patients (86.9\%) were treated nonsurgically (Fig. 1). The remaining patients were treated with surgery other than fusion procedures.

Because of privacy limitations, we are only able to report that between 1 and 11 patients were diagnosed with thoracic disc degeneration within 1,2, and 3 years of their initial fusion surgery (Fig. 1). In the thoracic nonsurgical 
TABLE 1. Procedural and diagnostic codes used to identify patients in the PearlDiver database*

\begin{tabular}{|c|c|c|}
\hline Description & Lumbar & Thoracic \\
\hline \multicolumn{3}{|l|}{ Fracture } \\
\hline Closed & ICD-9-D-8054 & ICD-9-D-8052 \\
\hline Open & ICD-9-D-8055 & ICD-9-D-8053 \\
\hline \multicolumn{3}{|l|}{ Fusion group } \\
\hline Lateral approach & CPT-22533, ICD-9-P-8107 & СРT-22522 \\
\hline Anterior approach & CPT-22558, ICD-9-P-8106 & CPT-22556, ICD-9-P-8104 \\
\hline Posterior approach & CPT-22612, ICD-9-P-8108 & CPT-22610, ICD-9-P-8105 \\
\hline \multicolumn{3}{|l|}{ Nonsurgical group } \\
\hline \multicolumn{3}{|l|}{ Excluded codes } \\
\hline Instrumentation procedures & $\begin{array}{l}\text { CPT-22840, CPT-22841, CPT-22842, CPT-22843, CPT-22844, } \\
\text { СРT-22849, СРT-22850, CPT-22851, СРT-22852, СРT-2285 }\end{array}$ & $\begin{array}{l}\text { PT-22845, CPT-22846, СРT-22847, CPT-22848, } \\
\text { СРT-22857, СРT-22862, СРT-22865 }\end{array}$ \\
\hline Other surgical procedures $†$ & 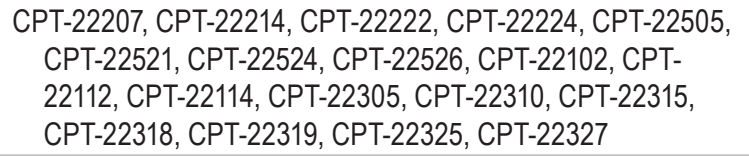 & 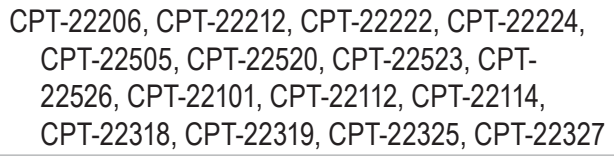 \\
\hline Disc degeneration & ICD-9-D-72252 & ICD-9-D-72251 \\
\hline \multicolumn{3}{|l|}{ Subsequent surgery } \\
\hline Lateral fusion & CPT-22533, ICD-9-P-8107 & \multirow{2}{*}{ CPT-22522 } \\
\hline Refusion & ICD-9-P-8137 & \\
\hline Anterior fusion & CPT-22558, ICD-9-P-8106 & CPT-22556, ICD-9-P-8104 \\
\hline Refusion & ICD-9-P-8136 & ICD-9-P-8134 \\
\hline Posterior fusion & CPT-22612, ICD-9-P-8108 & CPT-22610, ICD-9-P-8105 \\
\hline Refusion & ICD-9-P-8138 & ICD-9-P-8135 \\
\hline Instrumentation procedures & $\begin{array}{l}\text { СРT-22840, СРТ-22841, СРT-22842, СРТ-22843, СРT-22844, } \\
\text { СРT-22849, СРT-22850, СРT-22851, СРТ-22852, СРT-22855, }\end{array}$ & $\begin{array}{l}\text { PT-22845, СРT-22846, СРT-22847, CPT-22848, } \\
\text { ग-22857, СРT-22862, СРT-22865 }\end{array}$ \\
\hline
\end{tabular}

ICD-9-D = ICD-9 diagnostic code; ICD-9-P = ICD-9 procedural code.

* The table lists the codes used to identify patients with thoracic or lumbar fracture and delineate them into subgroups based on their listed treatment, codes used to exclude patients from the study groups, and the codes used to determine the number of patients who had subsequent disc degeneration diagnoses and needed fusion surgery.

$\dagger$ Open treatment of fracture, osteotomy, vertebroplasty.

group, 113 patients $(3.5 \%), 133(4.1 \%)$, and 147 (4.6\%) were diagnosed with thoracic disc degeneration within 1,2 , and 3 years, respectively.

No patient in the fusion group had a reoperation related to thoracic disc degeneration. Eleven patients from the nonsurgical group had a subsequent surgical procedure related to thoracic disc degeneration. This difference was not statistically significant ( $p>0.05$ ) according to chisquare analysis.

\section{Lumbar Region}

In 2007, 5016 patients were diagnosed with a lumbar fracture according to ICD-9 diagnostic codes (Fig. 4). Fifty-six percent of these patients were male, a trend consistent among all subgroups in the lumbar-fracture cohort (Fig. 2). The fracture diagnosis was most frequent for patients between the ages 15 and 19 years $(\mathrm{n}=653,13 \%)$, although it was also common for patients aged 55-59, 50 $54,60-64$, and $45-49$ years $(12.4 \%, 12.2 \%, 12.1 \%$, and $10.0 \%$ respectively, Fig. 3).

Of the 5016 patients diagnosed with lumbar fracture, 150 patients $(3.0 \%)$ were treated with a lumbar fusion pro- cedure within 90 days and 4371 (87.1\%) were treated nonsurgically (Fig. 4). It can be assumed that the remaining $9.9 \%$ of patients were treated with a surgical procedure other than fusion. There was no significant relationship $(p>0.05)$ between the demographic characteristics (age, sex, or region) and type of treatment (fusion or nonsurgical treatment).

Of the 150 patients who underwent lumbar fusion surgery, 28 (18.6\%), 34 (22.7\%), and 35 (23.3\%) were diagnosed with lumbar disc degeneration within 1,2 , and 3 years from the initial procedure (Fig. 4). Of the 4371 patients who were treated nonsurgically, 409 (9.4\%), 474 (10.8\%), and $503(11.5 \%)$ were diagnosed with lumbar disc degeneration within 1, 2, and 3 years (Fig. 4). The difference in the incidence of lumbar disc degeneration following fusion surgery was statistically significant $(p<0.05)$ for each of the first 3 years when compared with the incidence of degeneration following nonsurgical treatment, according to chi-square analysis.

As for subsequent operation rates, $42(1.0 \%)$ of the 4371 patients who were treated nonsurgically for a lumbar fracture ultimately underwent a surgical procedure in the 


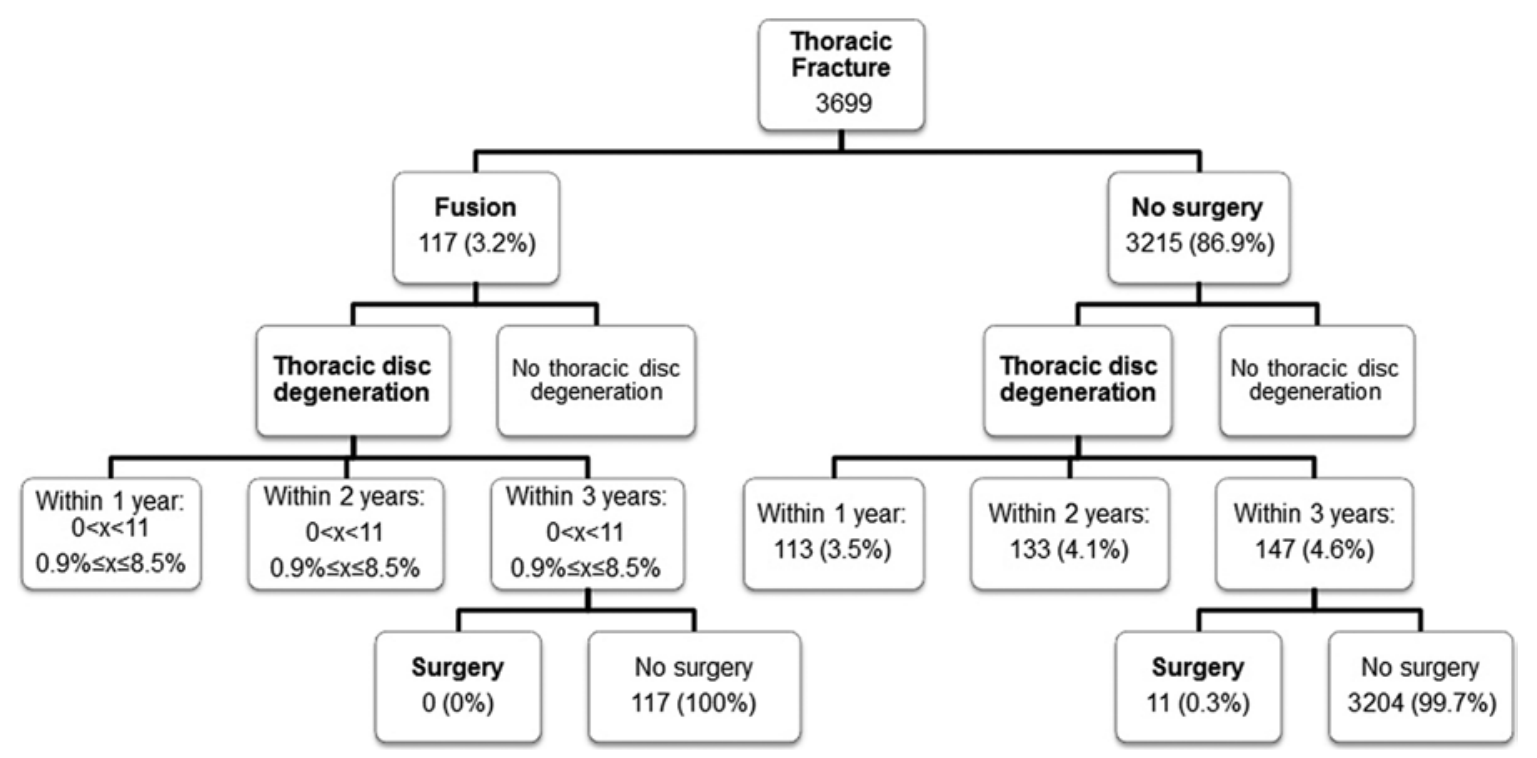

FIG. 1. Number of thoracic fracture patients in in the surgical and nonsurgical treatment subgroups. Most patients with thoracic fracture are treated nonsurgically rather than with fusion surgery. Following surgery, the greatest risk for disc degeneration is within the 1 st year.

lumbar spinal region related to disc degeneration (Fig. 4). Within the lumbar fusion group, there was at least 1 but fewer than 11 patients who underwent a reoperation, but due to the privacy limitations set by PearlDiver Inc. we are unable to publish the exact number.

\section{Discussion}

Our study indicates that fusion surgery as the initial treatment for thoracic fracture causes no statistically significant increase in the risk of undergoing a future surgery in the thoracic region, as compared with the risk for patients who are initially treated nonsurgically. Due to privacy limitations set in place by PearlDiver Inc., we could not gather data from enough patients to make a comparative conclusion about the rates of disc degeneration in the thoracic region.

In the lumbar region, however, we could make such comparisons regarding the rates of disc degeneration. Our data showed a statistically significant increase (approximately 2 -fold) in the levels of disc degeneration following

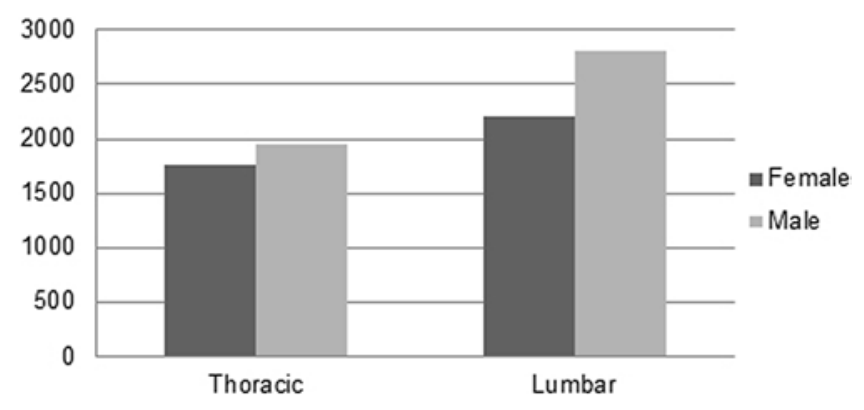

FIG. 2. Sex distribution of thoracic and lumbar fracture diagnoses. For each cohort, males outnumber females. lumbar fusion as opposed to nonsurgical treatment. That fusion surgery increased the risk of future lumbar disc degeneration is consistent with earlier publications. ${ }^{12,18}$

We excluded patients from the study who were diagnosed with disc degeneration at the time of their initial fracture. This allowed for a clearer comparison between the natural history of disc degeneration and the disc degeneration that was caused by the fracture or surgery itself. It is true, however, that some patients, especially the older ones, may have had degeneration that, although not indicated at the time of fracture, may have influenced their subsequent development of disc degeneration.

Again due to privacy limitations, we could not make an official comparison in the lumbar region between fusion and nonsurgical treatment in the rates of future surgery. However, we did draw upon the previous study by Sears et al. to extend our results about lumbar disc degeneration to rates of future surgery as well. Sears et al. reported that after fusion surgery, $2.5 \%$ of patients annually required another surgical procedure due to adjacent-level disc degeneration. ${ }^{18}$ We knew that at least 1 but fewer than 11 of the lumbar fusion patients in our study ultimately underwent a second surgical procedure. By using the $2.5 \%$ annual incidence rate from Sears et al., after 3 years, 11 patients would have undergone a future surgery. In our study, only 4 patients $(2.7 \%)$ were required in order to make the result significant according to chi-square analysis. This, combined with the fact that our study showed that the fusion group had a significantly larger $(p<0.05)$ incidence of lumbar disc degeneration than the nonoperative group, suggests that fusion in the lumbar region potentially leads to more issues than conservative treatment.

Furthermore, just in comparing the nonsurgical groups from both the thoracic and lumbar regions, we found that the patients who sustained lumbar fractures were nearly 3 times as likely as thoracic fracture patients to develop 


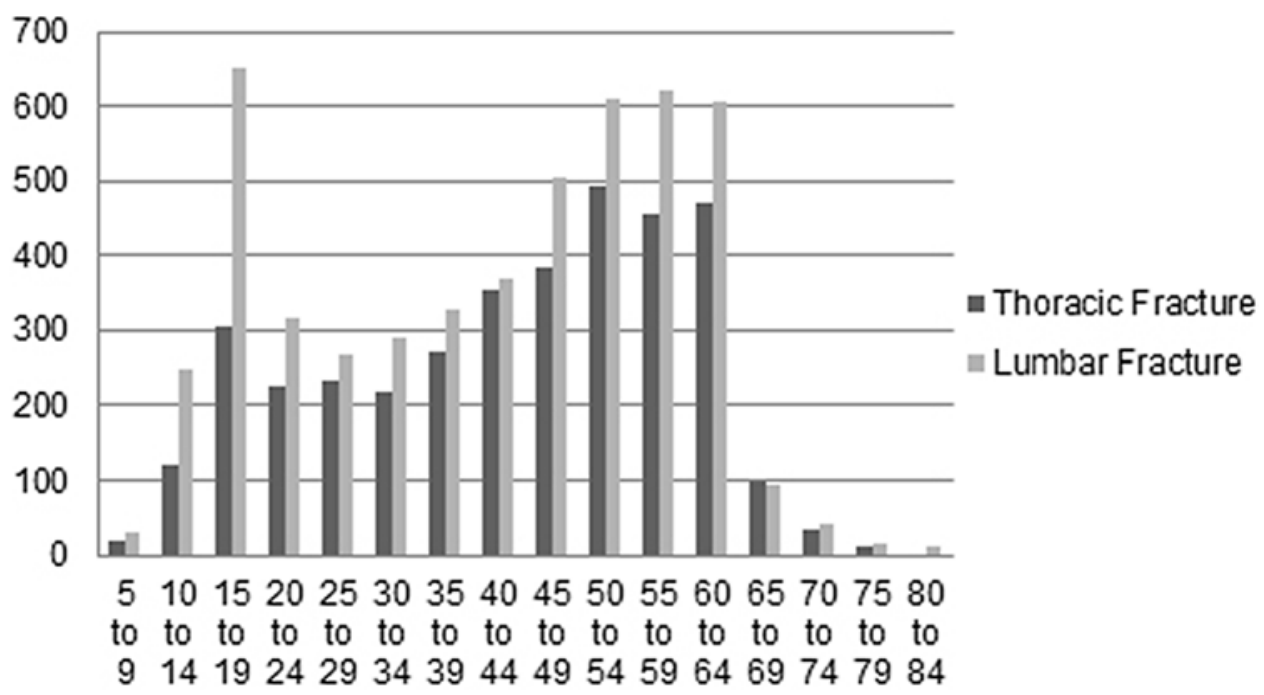

FIG. 3. Age distribution for lumbar and thoracic fractures. In the lumbar fracture cohort, the most common age range was 15-19 years (with $13.0 \%$ of the patients within this range), followed by $55-59$ years $(12.4 \%), 50-54$ years (12.2\%), and 60-64 years $(12.1 \%)$. In the thoracic fracture cohort, the most common age range was $50-54$ years (11.4\% of patients), followed by $60-64$ years $(11.0 \%)$ and then $55-59$ years $(10.2 \%)$. The number of lumbar fracture diagnoses outnumbers the number of thoracic fracture diagnoses for each age group.

disc degeneration in the same region after 1 year. This indicates that the lumbar region responds more dramatically to injury, at least in terms of disc degeneration. In light of this finding, the fact that the lumbar fusion group had a rate of disc degeneration nearly twice as high as the rate in the nonsurgical group may indicate that the effects of surgery were also more dramatic in the lumbar region than in the thoracic region.

Finally, the available data showed that for both the thoracic and lumbar regions the incidence of disc degeneration diagnoses was significantly higher in the 1st year following treatment than in the second or third years. These data suggest that if disc degeneration does not develop after one year, the likelihood of developing it in the future is greatly reduced.

While the strengths of this study include the large number of patients and its comparative nature, there are several limitations. First, the follow-up period spanned only 3 years. The fact that the yearly incidence of disc degeneration diagnoses (the presumed cause of additional surgery) sharply decreased in the lumbar-fracture group after the 1st year suggests, however, that longer-term studies may potentially corroborate these results. Also, because actual clinical patient records were not available through PearlDiver, we could only rely on available insurance billing codes. Although we isolated fractures to regions of the

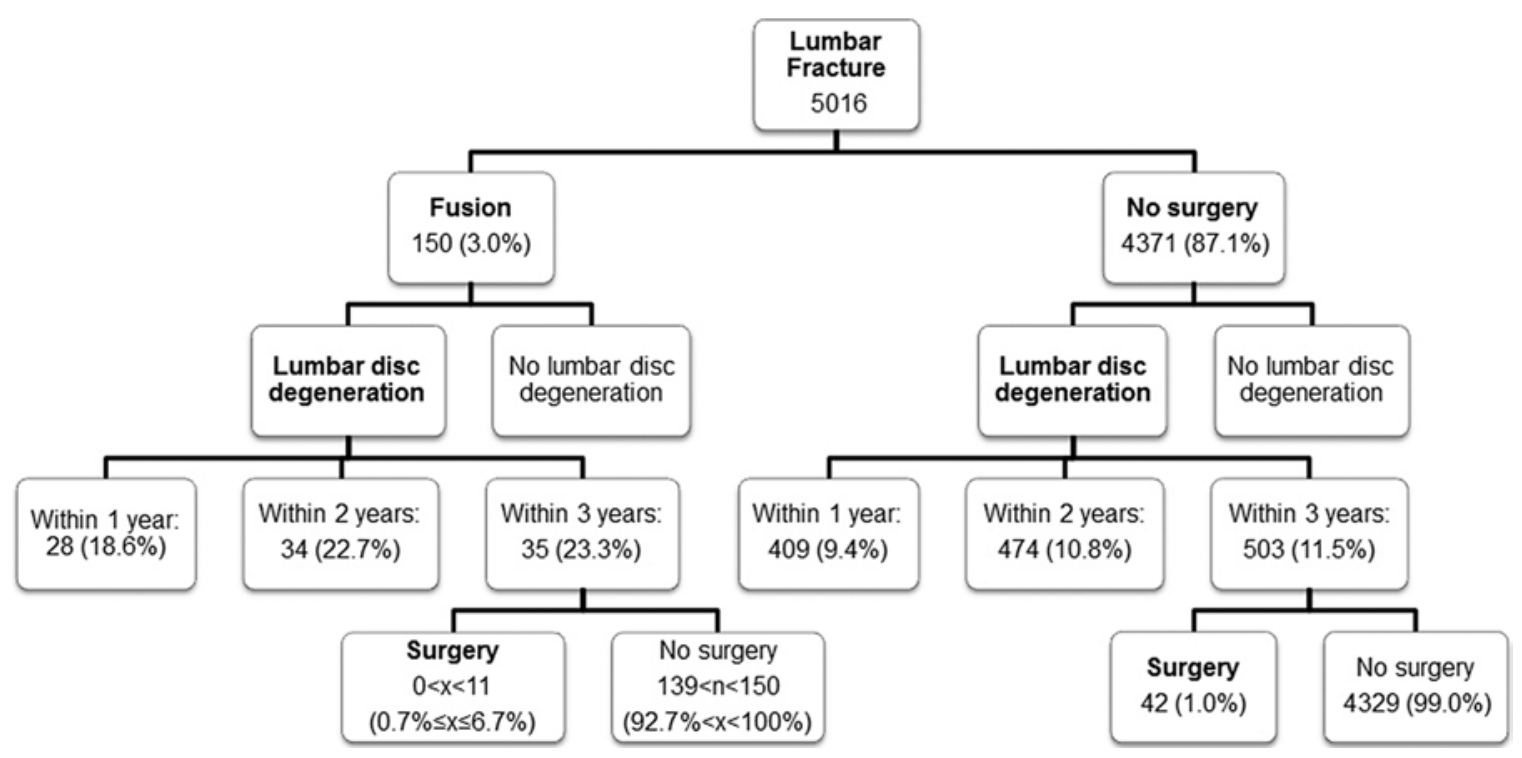

FIG. 4. Number of patients in each subgroup following a lumbar fracture diagnosis. Most patients are treated nonsurgically for lumbar fracture instead of with fusion surgery. The highest risk for disc degeneration is within the 1st year after treatment. 
spine (e.g., thoracic and lumbar), we could not specify their vertebral level or the vertebral level at which the subsequent degeneration diagnosis originated. Moreover, we could not code for the type or severity of fracture. While we did not include patients who also had a spinal cord injury-an indication for surgery-it is still probable that those who underwent fusion had more severe fractures. Finally, there was no definitive way of knowing that the patients who underwent subsequent surgery did so because of disc degeneration. These sources of error may have inflated the difference between the fusion and nonoperative groups in rates of subsequent surgery.

\section{Conclusions}

To our knowledge, this is the first study to make a direct comparison between fusion and nonsurgical treatments for both thoracic and lumbar fractures regarding the rates of subsequent surgery for disc degeneration. Based on the data from such a large pool of patients available through the PearlDiver database, we conclude that fusion surgery at the thoracic level does not significantly increase the risk of undergoing a future surgery as compared with nonsurgical treatment. We also conclude that fusion surgery increases the incidence of disc degeneration in the lumbar spine. We make no assertive declaration about the likelihood of needing an additional lumbar surgery due to privacy limitations. Still, we draw upon previous evidence (Sears et al.) and the data we gathered about rates of disc degeneration in the lumbar region to speculate that lumbar fusion may increase the risk of needing a future lumbar surgery related to disc degeneration. Future, longer-term studies with more clinical data that focus on incidence of reoperation rates linked to degeneration are needed.

\section{References}

1. Abudou M, Chen X, Kong X, Wu T: Surgical versus nonsurgical treatment for thoracolumbar burst fractures without neurological deficit. Cochrane Database Syst Rev 6:CD005079, 2013

2. Cantor JB, Lebwohl NH, Garvey T, Eismont FJ: Nonoperative management of stable thoracolumbar burst fractures with early ambulation and bracing. Spine (Phila Pa 1976) 18:971-976, 1993

3. Chow GH, Nelson BJ, Gebhard JS, Brugman JL, Brown CW, Donaldson DH: Functional outcome of thoracolumbar burst fractures managed with hyperextension casting or bracing and early mobilization. Spine (Phila Pa 1976) 21:2170-2175, 1996

4. Dickson JH, Harrington PR, Erwin WD: Results of reduction and stabilization of the severely fractured thoracic and lumbar spine. J Bone Joint Surg Am 60:799-805, 1978

5. Ekman P, Möller H, Shalabi A, Yu YX, Hedlund R: A prospective randomised study on the long-term effect of lumbar fusion on adjacent disc degeneration. Eur Spine J 18:11751186,2009

6. Ghiselli G, Wang JC, Bhatia NN, Hsu WK, Dawson EG: Adjacent segment degeneration in the lumbar spine. J Bone Joint Surg Am 86-A:1497-1503, 2004

7. Hitchon PW, Torner JC, Haddad SF, Follett KA: Management options in thoracolumbar burst fractures. Surg Neurol 49:619-627, 1998

8. Jacobs RR, Nordwall A, Nachemson A: Reduction, stability, and strength provided by internal fixation systems for thoracolumbar spinal injuries. Clin Orthop Relat Res (171):300308, 1982

9. Kraemer WJ, Schemitsch EH, Lever J, McBroom RJ, McKee MD, Waddell JP: Functional outcome of thoracolumbar burst fractures without neurological deficit. J Orthop Trauma 10:541-544, 1996

10. Lee CK: Accelerated degeneration of the segment adjacent to a lumbar fusion. Spine (Phila Pa 1976) 13:375-377, 1988

11. Lehmann TR, Spratt KF, Tozzi JE, Weinstein JN, Reinarz SJ, el-Khoury GY, et al: Long-term follow-up of lower lumbar fusion patients. Spine (Phila Pa 1976) 12:97-104, 1987

12. Mannion AF, Leivseth G, Brox JI, Fritzell P, Hägg O, Fairbank JC: Long-term follow up suggests spinal fusion is associated with increased adjacent segment disc degeneration but without influence on clinical outcome: results of a combined follow-up from 4 RCTs. Spine (Phila Pa 1976) 39:13731383, 2014

13. McLain RF, Sparling E, Benson DR: Early failure of shortsegment pedicle instrumentation for thoracolumbar fractures. A preliminary report. J Bone Joint Surg Am 75:162-167, 1993

14. Meyer PR Jr, Cotler HB: Fusion techniques for traumatic injuries, in Cotler JM, Cotler HB (eds): Spinal Fusion. New York: Springer, pp 189-246, 1990

15. Müller U, Berlemann U, Sledge J, Schwarzenbach O: Treatment of thoracolumbar burst fractures without neurologic deficit by indirect reduction and posterior instrumentation: bisegmental stabilization with monosegmental fusion. Eur Spine J 8:284-289, 1999

16. Penta M, Sandhu A, Fraser RD: Magnetic resonance imaging assessment of disc degeneration 10 years after anterior lumbar interbody fusion. Spine (Phila Pa 1976) 20:743-747, 1995

17. Schlegel JD, Smith JA, Schleusener RL: Lumbar motion segment pathology adjacent to thoracolumbar, lumbar, and lumbosacral fusions. Spine (Phila Pa 1976) 21:970-981, 1996

18. Sears WR, Sergides IG, Kazemi N, Smith M, White GJ, Osburg B: Incidence and prevalence of surgery at segments adjacent to a previous posterior lumbar arthrodesis. Spine $\mathbf{J}$ 11:11-20, 2011

19. Willén J, Lindahl S, Nordwall A: Unstable thoracolumbar fractures. A comparative clinical study of conservative treatment and Harrington instrumentation. Spine (Phila Pa 1976) 10:111-122, 1985

20. Wood K, Buttermann G, Mehbod A, Garvey T, Jhanjee R, Sechriest V: Operative compared with nonoperative treatment of a thoracolumbar burst fracture without neurological deficit. A prospective, randomized study. J Bone Joint Surg Am 85-A:773-781, 2003 (Erratum in J Bone Joint Surg Am 86-A:1283, 2004)

21. Wood KB, Buttermann GR, Phukan R, Harrod CC, Mehbod A, Shannon B, et al: Operative compared with nonoperative treatment of a thoracolumbar burst fracture without neurological deficit: a prospective randomized study with followup at sixteen to twenty-two years. J Bone Joint Surg Am 97:3-9, 2015

\section{Disclosure}

The authors report the following financial activities outside of the submitted work. Dr. Acosta reports a consultant relationship with NuVasive. Dr. Hsieh reports a consultant relationship with Medtronic and DePuy Synthes. Dr. Liu reports receiving travel and meeting support from AO Spine. Dr. Chen reports an ownership interest in NeOnc Technologies, Pharmaco-Kinesis, ERC, and Tocagen. Dr Wang reports receiving royalties from Stryker, Osprey, Aesculap, Biomet, Amedica, Seaspine, Synthes; stock 
ownership/private investments (no money paid, but options or personal investments) in Fziomed, Alphatec, Promethean Spine, Paradigm Spine, Benevenue, NexGen, Amedica, Vertiflex, ElectroCore, Surgitech, VG Innovations, CoreSpine, Expanding Orthopaedics, Osprey, Bone Biologics, Curative Biosciences, PearlDiver; being on the board of directors for North American Spine Society (nonfinancial, reimbursement for travel for board meetings, courses, etc.), North American Spine Foundation (nonfinancial), Cervical Spine Research Society (nonfinancial, reimbursement for travel for board meetings), AO Spine/AO

Foundation (honoraria for board and educational activities), Collaborative Spine Research Foundation (nonfinancial); and receiving fellowship support from AO Foundation (spine fellowship funding paid directly to institution/employer).

\section{Author Contributions}

Conception and design: Buser, D’Oro, Spoonamore, Wang. Acquisition of data: Cohen. Analysis and interpretation of data: Buser, D'Oro. Drafting the article: Buser, D'Oro. Critically revising the article: Buser, Spoonamore, Cohen, Acosta, Hsieh, Liu, Chen, Wang. Statistical analysis: D’Oro. Study supervision: Buser, Spoonamore, Wang.

\section{Correspondence}

Zorica Buser, Department of Orthopaedic Surgery, Keck School of Medicine, University of Southern California, Elaine Stevely Hoffman Medical Research Center, HMR 710, 2011 Zonal Ave., Los Angeles, CA 90033. email: zbuser@usc.edu. 